\section{BRAZIULIAN JOURNAL}

OF MEDICAL AND BIOLOGICAL RESFARCH

www.bjournal.com.br
ISSN 0100-879X

Volume 43 (5) 381-496 May 2011

BIOMEDICAL SCIENCES

AND

CLINICAL INVESTIGATION

Braz J Med Biol Res, May 2011, Volume 44(5) 438-444

doi: 10.1590/S0100-879X2011007500032

The methyl ester of rosuvastatin elicited an endothelium-independent and 3-hydroxy-3-methylglutaryl coenzyme A reductase-independent relaxant effect in rat aorta

J.S. López-Canales, P. López-Sanchez, V.M. Perez-Alvarez, I. Wens-Flores, A.C. Polanco,

E. Castillo-Henkel and C. Castillo-Henkel

The Brazilian Journal of Medical and Biological Research is partially financed by

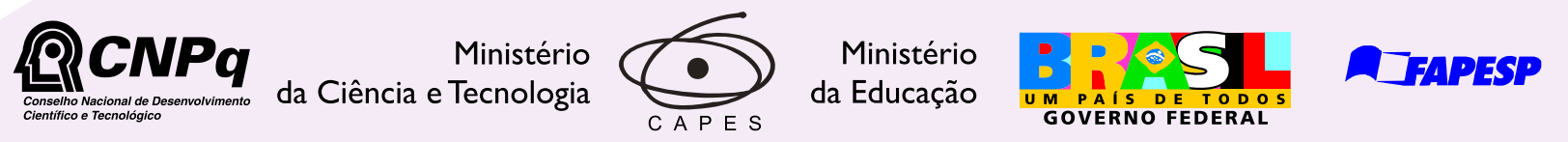

Institutional Sponsors
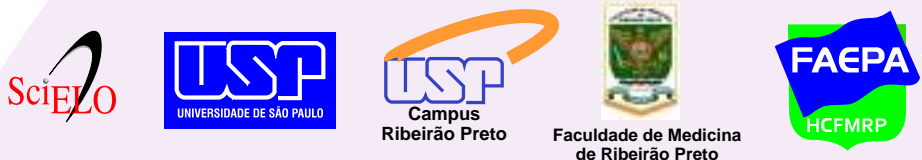

Ministério 


\title{
The methyl ester of rosuvastatin elicited an endothelium-independent and 3-hydroxy-3- methylglutaryl coenzyme A reductase- independent relaxant effect in rat aorta
}

\author{
J.S. López-Canales ${ }^{1,3}$, P. López-Sanchez ${ }^{1}$, V.M. Perez-Alvarez² ${ }^{2}$ I. Wens-Flores ${ }^{2}$, \\ A.C. Polanco ${ }^{4}$, E. Castillo-Henkel ${ }^{1}$ and C. Castillo-Henkel ${ }^{1}$ \\ ${ }^{1}$ Sección de Estudios de Posgrado e Investigación, Escuela Superior de Medicina, \\ I.P.N. Plan de San Luis y Díaz Mirón, Col. Casco de Sto. Tomás, México D.F., México \\ ${ }^{2}$ Centro de Investigación y Estudios Avanzados, Instituto Politécnico Nacional, \\ Unidad Zacatenco, México D.F., México \\ 3 Instituto Nacional de Perinatología, México D.F., México \\ ${ }^{4}$ Laboratorios Astra Zéneca, México D.F., México
}

\begin{abstract}
The relaxant effect of the methyl ester of rosuvastatin was evaluated on aortic rings from male Wistar rats (250-300 g, 6 rats for each experimental group) with and without endothelium precontracted with $1.0 \mu \mathrm{M}$ phenylephrine. The methyl ester presented a slightly greater potency than rosuvastatin in relaxing aortic rings, with log $\mathrm{IC}_{50}$ values of -6.88 and $-6.07 \mathrm{M}$, respectively. Unlike rosuvastatin, the effect of its methyl ester was endothelium-independent. Pretreatment with $10 \mu \mathrm{M}$ indomethacin did not inhibit, and pretreatment with $1 \mathrm{mM}$ mevalonate only modestly inhibited the relaxant effect of the methyl ester. N $\omega$-nitro-L-arginine methyl ester (L-NAME, $10 \mu \mathrm{M})$, the selective nitric oxide synthase-2 (NOS-2) inhibitor $1400 \mathrm{~W}(10 \mu \mathrm{M})$, tetraethylammonium (TEA, $10 \mathrm{mM})$, and cycloheximide $(10 \mu \mathrm{M})$ partially inhibited the relaxant effect of the methyl ester on endothelium-denuded aortic rings. However, the combination of TEA plus either L-NAME or cycloheximide completely inhibited the relaxant effect. Inducible NO synthase (NOS-2) was only present in endothelium-denuded aortic rings, as demonstrated by immunoblot with methyl ester-treated rings. In conclusion, whereas rosuvastatin was associated with a relaxant effect dependent on endothelium and hydroxymethylglutaryl coenzyme A reductase in rat aorta, the methyl ester of rosuvastatin exhibited an endotheliumindependent and only slightly hydroxymethylglutaryl coenzyme A reductase-dependent relaxant effect. Both NO produced by NOS- 2 and $\mathrm{K}^{+}$channels are involved in the relaxant effect of the methyl ester of rosuvastatin.
\end{abstract}

Key words: Rat aorta; Rosuvastatin methyl ester; Endothelium-independent relaxation; Potassium channels; NOS-2

\section{Introduction}

In addition to their beneficial lipid modulation effects, statins exert a variety of "pleiotropic" actions that may be clinically beneficial (1-3). Indeed, the pleiotropic effects of statins have been considered to be as important as their hypolipemiant effects in the prevention of cardiovascular diseases (4). Examples of the pleiotropic actions of statins such as pravastatin, cerivastatin, atorvastatin, simvastatin, and rosuvastatin (5-7) include direct acute vascular effects associated with increased production of either endothelial nitric oxide synthase (eNOS or NOS-3) in endothelial cells (8) or inducible NOS (iNOS or NOS-2) in smooth muscle cells (9), antithrombotic effects, anti-inflammatory effects $(10,11)$, and decreased nitrotyrosine production (12). A substantial number of experimental and clinical studies have demonstrated the favorable cardiovascular effects of rosuvastatin, one of the most commonly employed statins. These effects are generally associated with endothelial function. Rosuvastatin-elicited vasodilatation was mediated by the production of $\mathrm{NO}$ and the opening of $\mathrm{Ca}^{2+}$-dependent $\mathrm{K}^{+}$channels of the Slow subfamily (7). Several protective effects of this statin related to its vascular effects have been demonstrated, including the prevention of inflammation

Correspondence: C. Castillo-Henkel, Seccion de Estudios de Posgrado e Investigación, Escuela Superior de Medicina, I.P.N Plan de San Luis y Díaz Mirón, Col. Casco de Sto. Tomás, México D.F. 11340, México. E-mail: drcarloscastillo@hotmail.com

Received July 3, 2010. Accepted March 10, 2011. Available online March 25, 2011. Published May 16, 2011. 
and endothelial glycocalyx damage elicited by metalloproteinases, the inhibition of smooth muscle cell proliferation, the production of oxidized low-density lipoprotein, and an increase in plaque stability $(13,14)$.

The structure-activity relationships of statins regarding their hypolipemiant effect are clear (15). These drugs, through a mevalonic acid-like moiety, competitively inhibit 3-hydroxy-3-methylglutaryl coenzyme A (HMG-CoA) reductase, which catalyzes an early, rate-limiting step in the cholesterol biosynthesis (15). Independent of cholesterol synthesis, an interaction of statins with HMG-CoA may also be associated with several of the pleiotropic effects of these compounds (16). On the other hand, since information is scarce about the structural characteristics of statins that are responsible for their pleiotropic effects, we compared the relaxant effect of rosuvastatin and its methyl ester derivative on aortic rings.

\section{Material and Methods}

\section{Preparation of aortic rings}

Experiments were conducted under protocols approved by the Animal Care Committee of our institution (Escuela Superior de Medicina in agreement with the UK Animals Scientific Procedures Act of 1986).

Male Wistar rats (250-300 g) were kept in the animal colony until sacrificed. The animals were maintained on a 12-12-h light-dark cycle in a special room at constant temperature $\left(22 \pm 2^{\circ} \mathrm{C}\right)$, with food and water ad libitum.

The animals were euthanized by decapitation and the aortas were immediately excised and placed in Krebs-Henseleit bicarbonate cold buffer, cleaned and freed from surrounding connective tissue. The isolated arteries were cut into rings (4-5 mm long) and placed in 10-mL tissue chambers filled with Krebs-Henseleit bicarbonate buffer $(118 \mathrm{mM} \mathrm{NaCl}$, $4.7 \mathrm{mM} \mathrm{KCl}, 1.2 \mathrm{mM} \mathrm{KH}_{2} \mathrm{PO}_{4}, 1.2 \mathrm{mM} \mathrm{MgSO} 4 \cdot 7 \mathrm{H}_{2} \mathrm{O}, 2.5$ $\mathrm{mM} \mathrm{CaCl}_{2} \cdot 2 \mathrm{H}_{2} \mathrm{O}, 25 \mathrm{mM} \mathrm{NaHCO}_{3}, 11.7 \mathrm{mM}$ dextrose, and $0.026 \mathrm{mM}$ calcium disodium EDTA). In some experiments, the $\mathrm{KCl}$ concentration was increased to $80 \mathrm{mM}$ and the $\mathrm{Na}^{+}$ concentration was decreased to maintain osmotic equilibrium. Tissue baths, maintained at $37^{\circ} \mathrm{C}$ and $\mathrm{pH} 7.4$, were bubbled with a mixture of $95 \% \mathrm{O}_{2}$ and $5 \% \mathrm{CO}_{2}$.

Aortic rings were mounted on two stainless steel hooks to fix them to the bottom of the chamber and to a Grass FTO3 force displacement transducer connected to a 7D Grass Polygraph (Grass Instrument Co., USA) in order to record the isometric tension. Optimal tension, selected from preliminary experiments, was that which gave the greatest response to $1 \mu \mathrm{M}$ phenylephrine (Phen). The rings were submitted to $2 \mathrm{~g}$ initial tension and allowed to equilibrate for $2 \mathrm{~h}$. Thirty minutes after setting up the organ bath, tissues were first contracted with $1 \mu \mathrm{M}$ Phen to test their contractile responses. They were then rinsed three times with Krebs solution to restore tension to precontraction levels. Denuded aortic rings were used in some experiments.
Endothelium-denuded aortic strips were prepared by turning the rings gently several times on the distal portion of a small forceps. Endothelial integrity was pharmacologically assessed by $1 \mu \mathrm{M}$ acetylcholine-induced vasodilatation; segments showing no relaxation were considered to be endothelium-denuded.

All drugs were purchased from Sigma (USA). Rosuvastatin was a generous gift from Astra Zeneca, Mexico, and the methyl ester was synthesized in the Departamento de Farmacología, Centro de Investigación y Estudios Avanzados, Instituto Politécnico Nacional, Mexico, by employing rosuvastatin, iodomethane and ethanol in a biomolecular nucleophilic substitution reaction (SN2), carried out at room temperature, for $8 \mathrm{~h}$. The structure of the product was confirmed using $\mathrm{H}^{1}$ and $\mathrm{C}^{13}$ nuclear magnetic resonance.

\section{Experimental protocol}

After the equilibration period, dose-response curves were obtained for aortic rings with endothelium that were previously contracted with $1 \mu \mathrm{M}$ Phen, in order to determine whether the methyl ester of rosuvastatin ( $1 \mathrm{nM}$ to $10 \mu \mathrm{M})$ had a relaxant effect. The results for the methyl ester were compared with those obtained for rosuvastatin in order to establish their relative potencies.

Participation of the endothelial layer in the relaxant effect was studied by comparing the presence and absence of this tissue in aortic rings that were precontracted with Phen, then relaxed with rosuvastatin or its methyl ester. The results of these two agents were compared in order to establish the contribution of the endothelial layer.

Experiments were performed in order to determine if $\mathrm{NO}$, prostaglandins or $\mathrm{K}^{+}$channels are involved in the mechanism of the relaxant effect of the methyl ester of rosuvastatin. Aortic rings without endothelium were assayed in the presence or absence of the following inhibitors: $10 \mu \mathrm{M}$ L-NAME (a non-selective NOS inhibitor), $10 \mu \mathrm{M}$ indomethacin (a prostaglandin synthesis inhibitor), and 10 $\mathrm{mM}$ tetraethylammonium (TEA, a non-selective potassium channel blocker).

To establish whether NOS-2 activity and expression is involved in the relaxant effect of the methyl ester of rosuvastatin, three strategies were employed. The first consisted of evaluating the effect of this ester on denuded aortic rings pretreated with $1400 \mathrm{~W}$ (a selective NOS-2 inhibitor). The second was to determine the effect of this rosuvastatin derivative on aortic rings pretreated with 10 $\mu \mathrm{M}$ cycloheximide (a general protein synthesis inhibitor). The third was to obtain an immunoblot of iNOS in denuded aortic rings.

Finally, experiments were performed in order to evaluate the participation of HMG-CoA reductase in the effects of the methyl ester of rosuvastatin by pretreating aortic rings with $1 \mathrm{mM}$ mevalonic acid before administering the derivative of rosuvastatin. 


\section{NOS-2 immunoblot}

Briefly, samples were homogenized in Tris- $\mathrm{HCl}, \mathrm{pH} 7.4$, with a protease cocktail (MiniComplete-EDTA free, Roche, Germany) and total protein was analyzed by the method of Lowry et al. (17). Immunoblots were carried out in duplicate using $50 \mu$ g protein per lane on a $10 \%$ SDS-polyacrylamide gel and transferred onto polyvinylidene fluoride membrane (PVDF; Hybond-P, Amersham Biosciences, UK). The PVDF membrane was then blocked with TBS containing $5 \%$ skim milk and $0.05 \%$ Tween for $2 \mathrm{~h}$ at room temperature. The blot was incubated overnight at $4^{\circ} \mathrm{C}$ with a polyclonal antibody against iNOS (Santa Cruz Biotechnology, USA) at a final dilution of 1:400. We previously tested that this antibody was NOS-2-specific and did not cross-react with NOS-1 or NOS-3. The membrane was then washed and incubated with the corresponding secondary (anti-rabbit) horseradish peroxidase-labeled antibody (Zymed), diluted $1: 10,000$ in blocking solution, for $2 \mathrm{~h}$ at room temperature. Blots were washed and developed using an ECL detection system (Luminol, Santa Cruz Biotechnology). The blots were stripped and reproved with a $\beta$-actin polyclonal antibody as a control. Images were digitally acquired from films and a densitometric analysis was performed using the Quantity One Image Acquisition and Analysis Software (BioRad, USA). Data are reported as normalized absorbance.

\section{Statistical analysis}

Data are reported as means \pm SEM for 6 animals in each experiment. Statistical comparisons were performed by two-way ANOVA followed by the post hoc Bonferroni test. In all cases, a $P$ value of less than 0.05 was considered to be statistically significant. Data were analyzed statistically using the Prism 4.0 software (Graph Pad Software, USA).

\section{Results}

\section{Comparative analysis of the effect of rosuvastatin} and its methyl ester on precontracted aortic rings

Rosuvastatin and the methyl ester of rosuvastatin (1 $\mathrm{nM}-10 \mu \mathrm{M}$ ) elicited a concentration-dependent relaxation of aortic rings precontracted with Phen (data not show). The maximum effects of the methyl ester and rosuvastatin were not different $\left(E_{\text {Max }}\right.$ values $\left.=91 \%\right)$ but the potency of the methyl ester $\left(\log \mathrm{IC}_{50}=-6.88 \mathrm{M}\right)$ was higher than that of rosuvastatin $\left(\log \mathrm{IC}_{50}=-6.071 \mathrm{M}\right)$.

Influence of endothelium on the relaxant effect of the methyl ester of rosuvastatin on precontracted aortic rings

Figure 1 shows the effects of the methyl ester of rosuvastatin (A) or rosuvastatin (B) on aortic rings precontracted with Phen, with and without endothelium. Removal of the endothelium did not affect the magnitude of the effect of the methyl ester derivative (maximal relaxations were 82.42 \pm 1.10 vs $80.49 \pm 2.62 \%$ in the presence and absence of endothelium, respectively). Contrary to the results with the methyl ester, the effect of rosuvastatin was partially inhibited after endothelium removal $\left(\mathrm{E}_{\text {Max }}\right.$ was $80.05 \pm 1.25 \mathrm{vs}$ $40 \pm 3.47 \%$; in the presence and absence of endothelium, respectively).

\section{Effects of L-NAME, $1400 \mathrm{~W}$ and indomethacin on the} relaxant effect induced by the methyl ester of rosuvastatin on denuded aortic rings

As shown in Figure 2, pretreatment with L-NAME (a nonselective NOS inhibitor; A), or 1400 W (a selective NOS-2 inhibitor; B) significantly reduced the relaxant effect of the methyl ester of rosuvastatin on aortic rings. The maximal relaxant effect was $39.36 \pm 3.40$ vs $80.49 \pm 2.62 \%$ for the control in the first case, and $25.0 \pm 3.61$ vs $84.84 \pm 3.02 \%$ for the control in the second case. Furthermore, aortic rings precontracted with Phen and exposed to a high concentration of the methyl ester of rosuvastatin $(10 \mu \mathrm{M})$ showed immediate relaxation, which reached its maximum at 20 min and was inhibited in the presence of $1400 \mathrm{~W}$ (data not shown). Finally, pretreatment with indomethacin (a pros-
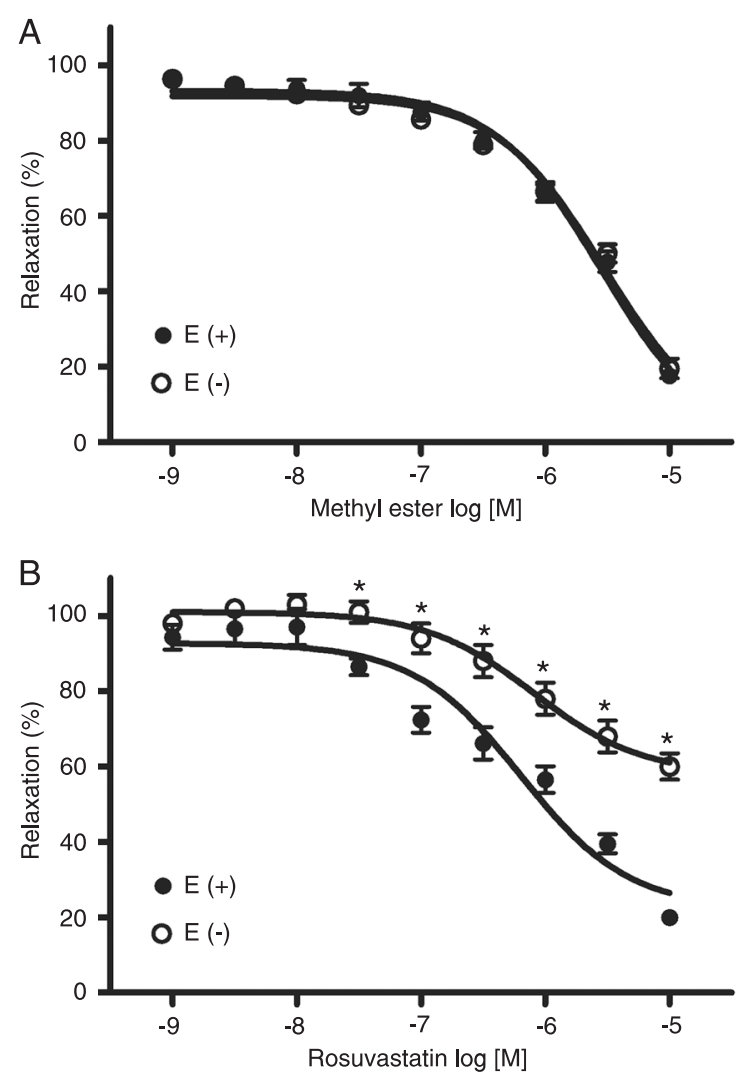

Figure 1. Relaxant effects of methyl ester $(A)$ or rosuvastatin $(B)$ on rat aortic rings with $[E(+)]$ or without $[E(-)]$ endothelium precontracted with $1 \mu \mathrm{M}$ phenylephrine. Data are reported as means \pm SEM for $\mathrm{N}=6$ experiments. ${ }^{*} \mathrm{P}<0.001$ compared to $\mathrm{E}(+)$ (twoway ANOVA). 
taglandin synthesis inhibitor) did not modify the relaxant effect of the methyl ester (data not shown).

\section{Participation of $\mathrm{K}^{+}$channels in the relaxant effect of the methyl ester}

The effect of the methyl ester of rosuvastatin on denuded aortic rings precontracted with Phen was evaluated in the presence and absence of $10 \mathrm{mM} \mathrm{TEA}, \mathrm{a} \mathrm{K}^{+}$channel blocker. As shown in Figure 3A, pretreatment with TEA inhibited the relaxation induced by the statin. The maximal relaxant effect was $93.28 \pm 3.92 \%$ without TEA, and $33.25 \pm 6.01 \%$ with TEA. Furthermore the combination of L-NAME and TEA almost completely inhibited the relaxant effect of the methyl ester (Figure 3B).

\section{Participation of protein synthesis in the relaxant effect of the methyl ester}

As shown in Figure 4A, pretreatment with cycloheximide, a protein synthesis inhibitor, significantly reduced the maximum relaxant effect of the methyl ester of rosuvastatin
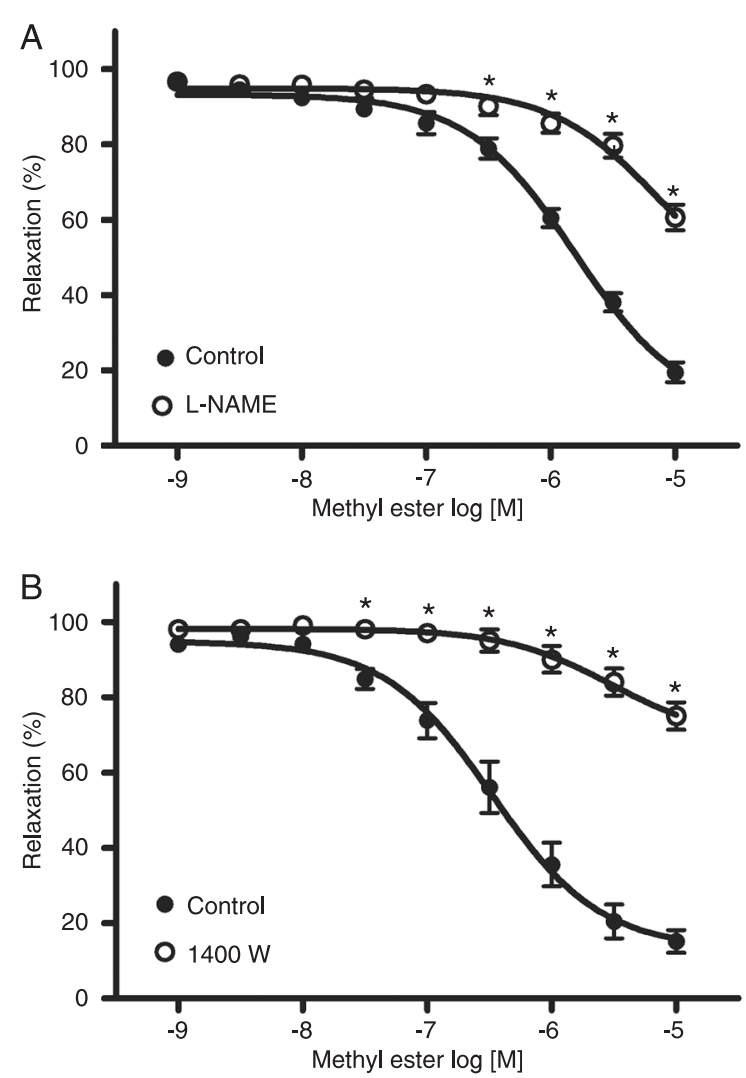

Figure 2. Effect of $(A)$ L-NAME $(10 \mu M)$ or $(B) 1400 \mathrm{~W}(10 \mu M)$ on methyl ester-induced relaxation of rat aortic rings without endothelium precontracted with $1 \mu \mathrm{M}$ phenylephrine. Data are reported as means \pm SEM for $N=6$ experiments. ${ }^{*} \mathrm{P}<0.01 \mathrm{com}-$ pared to control (two-way ANOVA). on denuded aortic rings. $E_{\text {Max }}$ was $85.15 \pm 2.52 \%$ without cycloheximide and $28 \pm 3.19 \%$ with this inhibitor. When cycloheximide and TEA were administered together, the relaxant effect of the methyl ester was almost completely inhibited (Figure 4B). On the other hand, cycloheximide did not alter sodium nitroprusside-induced relaxation in endothelium-intact and endothelium-denuded aortic rings (data not shown). Thus, the possibility that cycloheximide might inhibit relaxing agents through a mechanism unrelated to the inhibition of protein synthesis is ruled out.

\section{Participation of HMG-CoA reductase in the relaxant effect of the methyl ester}

As shown in Figure 5, pretreatment with mevalonic acid (the product of enzymatic conversion of HMG-CoA) (5) elicited only a partial inhibition of the relaxant effect of rosuvastatin or its methyl ester on denuded aortic rings. This partial inhibition was lesser in the case of the methyl ester (significant only in the last 3 points of the curve). The $\mathrm{E}_{\text {Max }}$ was $88.83 \pm 1.99$ and $88.59 \pm 1.68 \%$ in the absence
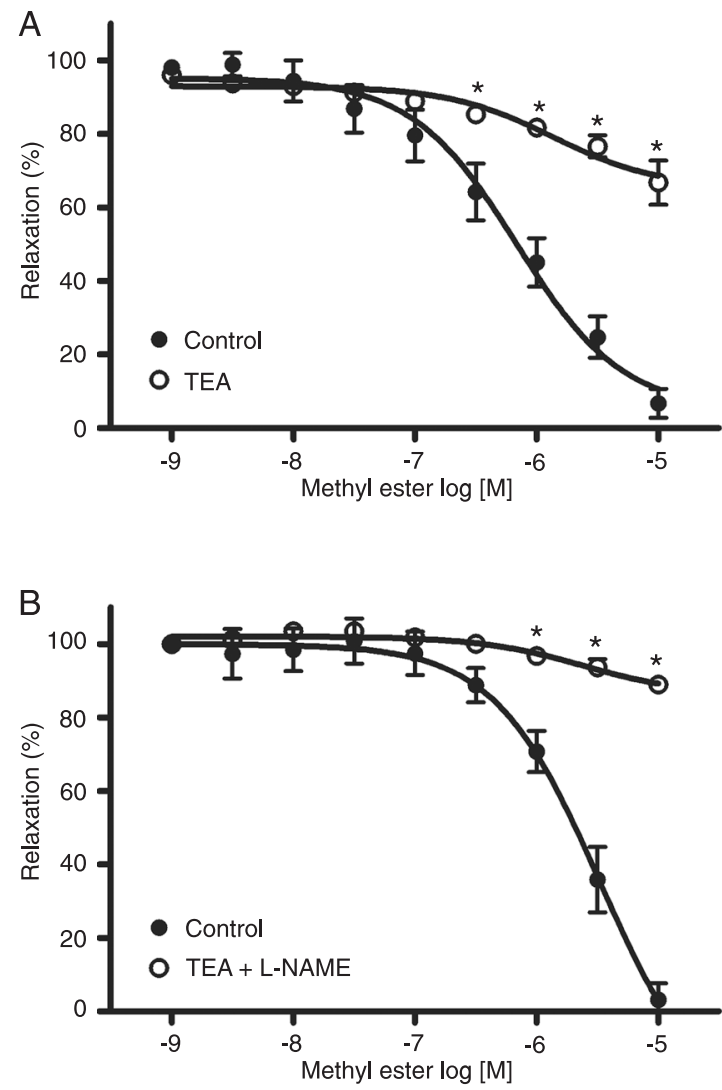

Figure 3. Effect of (A) $10 \mathrm{mM}$ tetraethylammonium (TEA) or (B) $10 \mathrm{mM}$ TEA plus $10 \mu \mathrm{M}$ L-NAME on methyl ester-induced relaxation of rat aortic rings without endothelium precontracted with 1 $\mu \mathrm{M}$ phenylephrine. Data are reported as means \pm SEM for $\mathrm{N}=6$ experiments. ${ }^{*} \mathrm{P}<0.001$ compared to control (two-way ANOVA). 
of mevalonate and $46.94 \pm 2.62$ and $74.0 \pm 2.28 \%$ in the presence of mevalonate in the case of rosuvastatin and its methyl ester, respectively.

\section{Immunoblot}

NOS-2 protein expression was assayed using specific antibody against the enzyme. This antibody was tested to ensure that it did not cross-react with a different enzyme subtype. NOS-2 was expressed in thoracic aortic segments. When Phen was added to both tissues, the relative NOS-2 expression did not change significantly. When the methyl ester was added, however, NOS-2 expression significantly increased (Figure 6).

\section{Discussion}

The results of the present study clearly show that the methyl ester of rosuvastatin has an acute concentrationdependent relaxant effect on vascular smooth muscle,
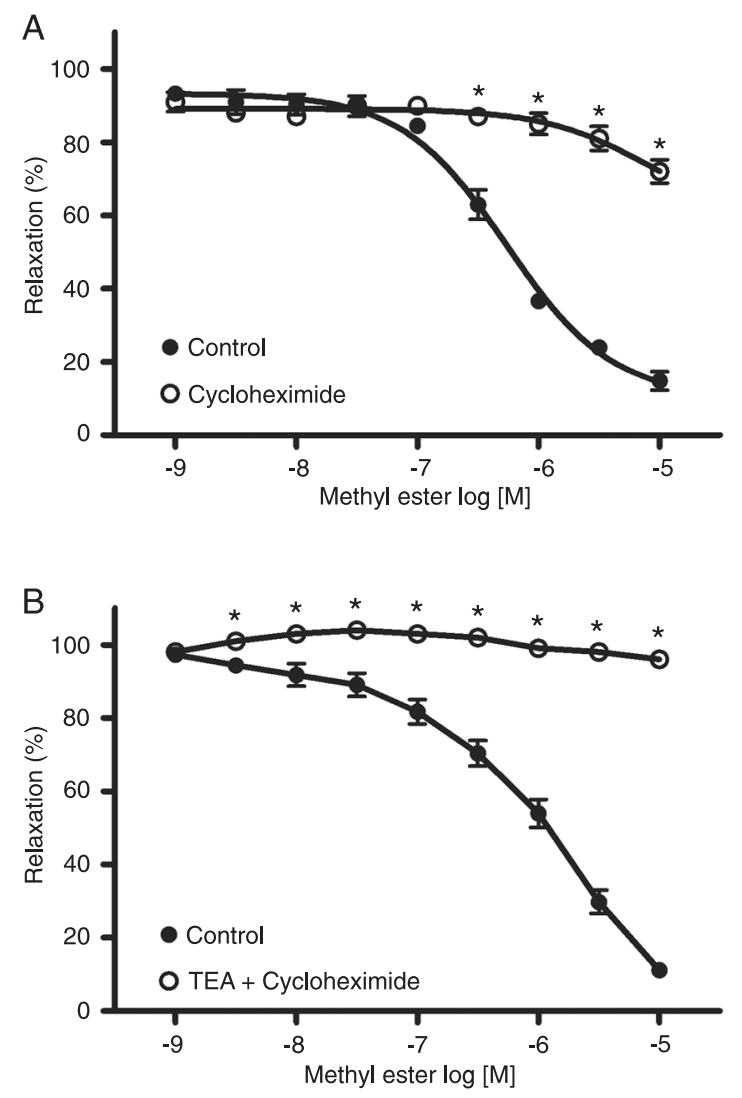

Figure 4. Effect of (A) $10 \mathrm{mM}$ cycloheximide or (B) $10 \mathrm{mM}$ cycloheximide plus $10 \mathrm{mM}$ tetraethylammonium (TEA) on methyl ester-induced relaxation of rat aortic rings without endothelium precontracted with $1 \mu \mathrm{M}$ phenylephrine. Data are reported as means \pm SEM for $N=6$ experiments. ${ }^{*} P<0.001$ compared to control (two-way ANOVA).
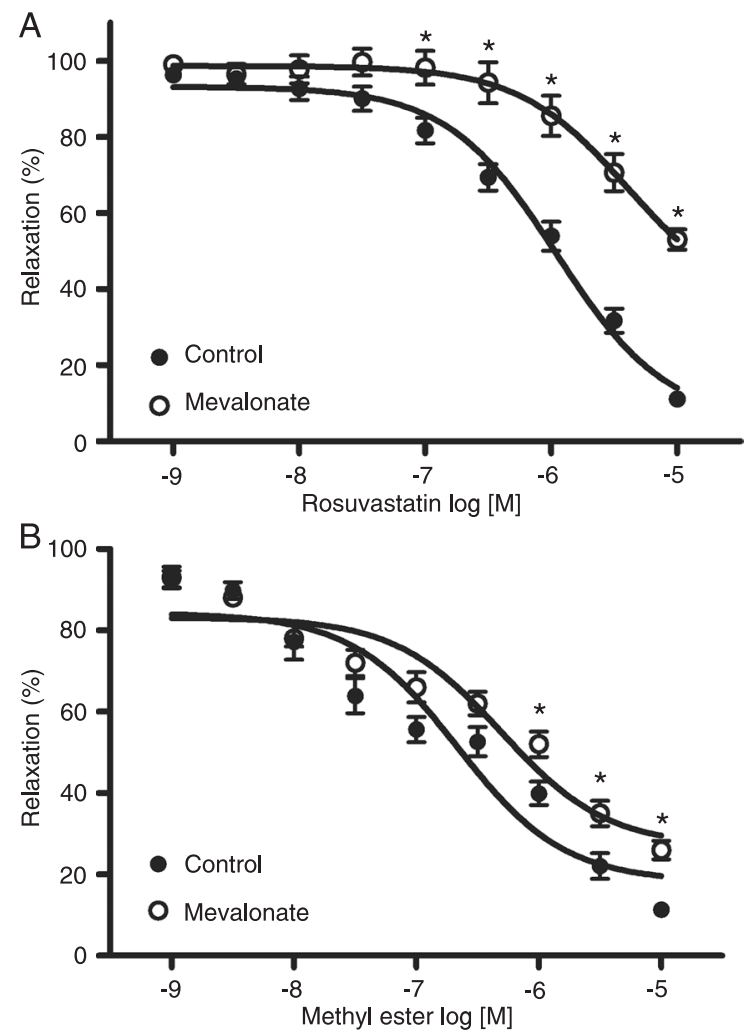

Figure 5. Effect of $1 \mathrm{mM}$ mevalonate on (A) rosuvastatin- or (B) methyl ester-induced relaxation of rat aortic rings without endothelium precontracted with $1 \mu \mathrm{M}$ phenylephrine. Data are reported as means \pm SEM for $N=6$ experiments. ${ }^{*} P<0.05$ compared to control (two-way ANOVA).
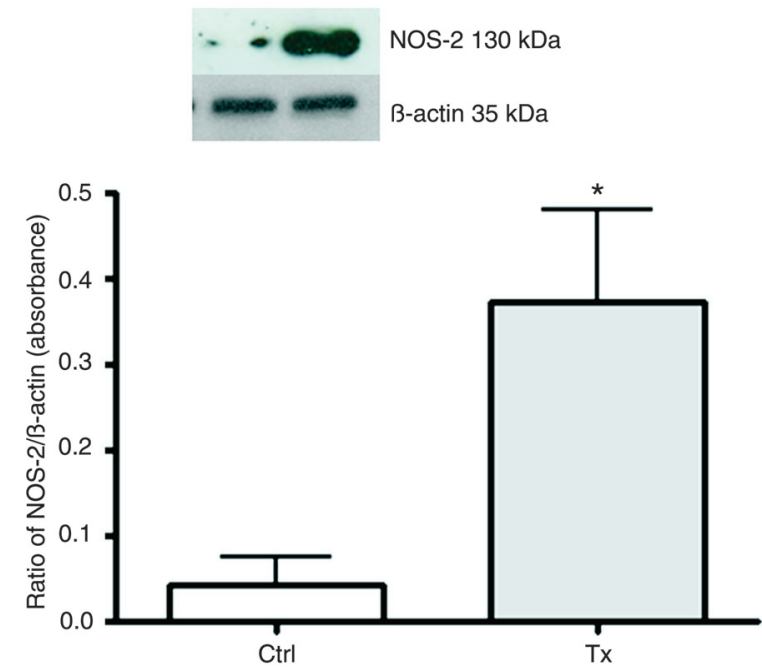

Figure 6. iNOS expression in the rat aorta. Data are reported as means \pm SEM for 3-4 rats. Ctrl = control (only phenylephrine); $T \mathrm{x}=$ treatment (phenylephrine plus rosuvastatin methyl ester). Insert shows results from a typical experiment. * $P<0.05 \mathrm{com}-$ pared to control (two-way ANOVA). 
in agreement with previous reports on rosuvastatin and several other statins (5-7). Although the methyl ester was slightly more potent than rosuvastatin, the maximal effects of these two agents were similar. Interestingly, the relaxant effect of the methyl ester is independent of the endothelial layer, even though the relaxant effect of rosuvastatin is partially endothelium-dependent $(7,18)$. Accordingly, the structural modification of rosuvastatin seems to be associated with a loss of its effect on the endothelium and an increase in the endothelium-independent effect, leading to an overall maximum relaxant effect without any significant change.

We evaluated the participation of $\mathrm{NO}$ and prostaglandins by pretreating denuded aortic rings with L-NAME and indomethacin, respectively, to obtain information about the mechanism of the relaxant effect of the methyl ester of rosuvastatin. Whereas L-NAME partially but significantly inhibited the relaxant effect, indomethacin had no effect. These results strongly suggest that NO produced by vascular smooth muscle cells is involved in the relaxant effect of the methyl ester, while prostaglandins apparently play no role.

Because only partial inhibition was obtained with LNAME, another mechanism in addition to NO production is likely to be involved in the relaxant effect of the methyl ester of rosuvastatin. Since a previous report by our group demonstrated that rosuvastatin can open $\mathrm{K}^{+}$channels, we suspected that this could be a complementary mechanism for NO production in the relaxant effect of rosuvastatin and its derivative (7). The results obtained with TEA in denuded aortic rings confirm that $\mathrm{K}^{+}$channels located in vascular smooth muscle cells are involved in the relaxant effect of the methyl ester. The complementary or additive role of $\mathrm{NO}$ and $\mathrm{K}^{+}$channels in the effect of this compound is demonstrated by the fact that simultaneous pretreatment with TEA and L-NAME almost completely inhibited the relaxant effect of the methyl ester.

Because NOS-2 is the NOS isoform present in smooth muscle cells $(19,20)$, we hypothesized that the L-NAMEsensitive component of the relaxant effect of the methyl ester may result from the ability of this compound to induce this enzyme. Thus, endothelium-denuded aortic rings were pretreated with either $1400 \mathrm{~W}$ (a selective NOS-2 inhibitor) or cycloheximide (a protein synthesis inhibitor) before administration of the methyl ester, resulting in a partial inhibition, of the relaxant effect in both cases. This suggests that NO produced by recently synthesized NOS-2 is involved in the effect of the methyl ester. On the other hand, combined pretreatment with cycloheximide and TEA completely inhibited the relaxant effect, confirming that NO produced by NOS-2, as well as $\mathrm{K}^{+}$channels, are involved in the effect of the methyl ester. Additional support for the existence of these two mechanisms, and suggesting that NOS-2 is located in vascular smooth muscle, is the fact that this enzyme was detected by immunoblot only after methyl ester pretreatment of the denuded aortic artery.

The results of the present study suggest that the methyl ester induces NOS-2 expression within a shorter time than that suggested by various investigators, who have reported that several hours are required for the expression of iNOS to increase after exposure to an agent that prompts its induction $(21,22)$. Nevertheless, there is a report (23) of increased iNOS expression within a shorter time.

The immunoblot results of the present study were obtained in cell culture $3 \mathrm{~h}$ after incubation with the first concentration of the methyl ester of rosuvastatin, enough time for NOS-2 expression according to the generally accepted concept. However, the fact that a relaxant effect was observed quickly and reached its maximum level within 20 min after exposure of aortic rings to a high concentration of the methyl ester of rosuvastatin, and that this effect was inhibited in the presence of $1400 \mathrm{~W}$, supports the idea that this compound has a relatively rapid inducing effect on NOS-2.

Perhaps it is necessary to reconsider the role of iNOS in the regulation of vascular tone, taking into account that in some cases the participation of this enzyme does not need to be a product of a triggering stimulant related to inflammation. Accordingly, it has been suggested that the original idea of constitutive synthases be modified: "The paradigm of constitutive NOS and iNOS isoforms has been modified from its original conception: although neuronal NOS (nNOS) and eNOS are constitutively expressed, it is now clear that their activity can be regulated by various factors" (24). Then, iNOS may not always be a product of induction, nor always be associated with pathological conditions.

Results obtained in the presence of mevalonic acid are particularly important because they strongly suggest that the methyl ester of rosuvastatin has HMG-CoA reductase-independent pleiotropic effects. This contention is supported by the observation that pretreatment with mevalonic acid elicited only a mild inhibitory effect on the endothelium-independent vasodilator effect of the methyl ester of rosuvastatin.

The present results show that structural modification of rosuvastatin elicited a qualitative but not quantitative change in its relaxant effect on vascular smooth muscle. Whereas this structural modification decreased the endotheliumdependent component, it increased the endothelium-independent component of this effect. Further experiments are needed to clarify the mechanisms involved in these changes, as well as the relationship between these changes and the structural modification of rosuvastatin. On the basis of these results, we suggest that some pleiotropic actions of statins are independent of HMG-CoA reductase.

We conclude that, compared to rosuvastatin, its methyl ester elicited a qualitative but not quantitative change in the relaxant effect on aortic rings. Whereas rosuvastatin is associated with an endothelium- and hydroxymethylglutaryl coenzyme A reductase-dependent relaxant effect 
in rat aorta, the methyl ester of rosuvastatin exhibited an endothelium-independent and only partially hydroxymethylglutaryl coenzyme A reductase-dependent relaxant effect.

\section{References}

1. Brown BG, Zhao XQ, Sacco DE, Albers JJ. Lipid lowering and plaque regression. New insights into prevention of plaque disruption and clinical events in coronary disease. Circulation 1993; 87: 1781-1791.

2. Jukema JW, Bruschke AV, van Boven AJ, Reiber JH, Bal ET, Zwinderman $\mathrm{AH}$, et al. Effects of lipid lowering by pravastatin on progression and regression of coronary artery disease in symptomatic men with normal to moderately elevated serum cholesterol levels. The Regression Growth Evaluation Statin Study (REGRESS). Circulation 1995; 91: 2528-2540.

3. Riegger G, Abletshauser C, Ludwig M, Schwandt P, Widimsky J, Weidinger $G$, et al. The effect of fluvastatin on cardiac events in patients with symptomatic coronary artery disease during one year of treatment. Atherosclerosis 1999; 144: 263-270.

4. Corsini A, Pazzucconi F, Arnaboldi L, Pfister P, Fumagalli R, Paoletti $R$, et al. Direct effects of statins on the vascular wall. J Cardiovasc Pharmacol 1998; 31: 773-778.

5. Alvarez De Sotomayor M, Herrera MD, Marhuenda E, Andriantsitohaina R. Characterization of endothelial factors involved in the vasodilatory effect of simvastatin in aorta and small mesenteric artery of the rat. Br J Pharmacol 2000; 131: 1179-1187.

6. Sonmez Uydes-Dogan B, Topal G, Takir S, Ilkay AF, Kaleli $D$, Ozdemir O. Relaxant effects of pravastatin, atorvastatin and cerivastatin on isolated rat aortic rings. Life Sci 2005; 76: 1771-1786.

7. Lopez J, Mendoza R, Cleva VG, Martinez G, Castillo EF, Castillo C. Participation of $\mathrm{K}+$ channels in the endotheliumdependent and endothelium-independent components of the relaxant effect of rosuvastatin in rat aortic rings. J Cardiovasc Pharmacol Ther 2008; 13: 207-213.

8. Laufs U, La Fata V, Plutzky J, Liao JK. Upregulation of endothelial nitric oxide synthase by HMG CoA reductase inhibitors. Circulation 1998; 97: 1129-1135.

9. Kolyada AY, Fedtsov A, Madias NE. 3-Hydroxy-3-methylglutaryl coenzyme A reductase inhibitors upregulate inducible NO synthase expression and activity in vascular smooth muscle cells. Hypertension 2001; 38: 1024-1029.

10. Vaughan CJ, Delanty N. Neuroprotective properties of statins in cerebral ischemia and stroke. Stroke 1999; 30: 1969-1973.

11. Ridker PM, Danielson E, Fonseca FA, Genest J, Gotto AM $\mathrm{Jr}$, Kastelein JJ, et al. Rosuvastatin to prevent vascular events in men and women with elevated C-reactive protein. N Engl J Med 2008; 359: 2195-2207.

12. Tannous M, Cheung R, Vignini A, Mutus B. Atorvastatin increases ecNOS levels in human platelets of hyperlipidemic
The relaxant effect of the methyl ester was mediated by the NO produced by iNOS located in vascular smooth muscle, as well as by $\mathrm{K}^{+}$channel activation. subjects. Thromb Haemost 1999; 82: 1390-1394.

13. Kostapanos MS, Milionis HJ, Elisaf MS. An overview of the extra-lipid effects of rosuvastatin. J Cardiovasc Pharmacol Ther 2008; 13: 157-174.

14. Meuwese MC, Mooij HL, Nieuwdorp M, van Lith B, Marck R, Vink $\mathrm{H}$, et al. Partial recovery of the endothelial glycocalyx upon rosuvastatin therapy in patients with heterozygous familial hypercholesterolemia. J Lipid Res 2009; 50: 148153.

15. Istvan ES, Deisenhofer J. Structural mechanism for statin inhibition of HMG-CoA reductase. Science 2001; 292: 11601164.

16. Maron DJ, Fazio S, Linton MF. Current perspectives on statins. Circulation 2000; 101: 207-213.

17. Lowry $\mathrm{OH}$, Rosebrough NJ, Farr AL, Randall RJ. Protein measurement with the Folin phenol reagent. $J$ Biol Chem 1951; 193: 265-275.

18. Schafer A, Fraccarollo D, Vogt C, Flierl U, Hemberger M, Tas $\mathrm{P}$, et al. Improved endothelial function and reduced platelet activation by chronic HMG-CoA-reductase inhibition with rosuvastatin in rats with streptozotocin-induced diabetes mellitus. Biochem Pharmacol 2007; 73: 1367-1375.

19. Luoma JS, Stralin P, Marklund SL, Hiltunen TP, Sarkioja T, Yla-Herttuala S. Expression of extracellular SOD and iNOS in macrophages and smooth muscle cells in human and rabbit atherosclerotic lesions: colocalization with epitopes characteristic of oxidized LDL and peroxynitrite-modified proteins. Arterioscler Thromb Vasc Biol 1998; 18: 157-167.

20. Muniyappa R, Xu R, Ram JL, Sowers JR. Inhibition of Rho protein stimulates iNOS expression in rat vascular smooth muscle cells. Am J Physiol Heart Circ Physiol 2000; 278: H1762-H1768.

21. Nakata S, Tsutsui M, Shimokawa H, Yamashita T, Tanimoto A, Tasaki $\mathrm{H}$, et al. Statin treatment upregulates vascular neuronal nitric oxide synthase through Akt/NF-kappaB pathway. Arterioscler Thromb Vasc Biol 2007; 27: 92-98.

22. Kosmidou I, Moore JP, Weber M, Searles CD. Statin treatment and 3' polyadenylation of eNOS mRNA. Arterioscler Thromb Vasc Biol 2007; 27: 2642-2649.

23. Chittezhath M, Deep G, Singh RP, Agarwal C, Agarwal R. Silibinin inhibits cytokine-induced signaling cascades and down-regulates inducible nitric oxide synthase in human lung carcinoma A549 cells. Mol Cancer Ther 2008; 7: 18171826.

24. Alderton WK, Cooper CE, Knowles RG. Nitric oxide synthases: structure, function and inhibition. Biochem J 2001; 357: 593-615. 